\title{
Pervasive Learning and Technology Usage for Creativity Development in Education
}

\author{
https://doi.org/10.3991/ijet.v14i01.9067 \\ Ivanna Shubina ${ }^{(凶)}$, Atik Kulakli \\ American University of the Middle East, Kuwait \\ ivanna.shubina@aum.edu.kw / ivannashubina@gmail.com
}

\begin{abstract}
This paper's aim is to investigate the role of creativity and pervasive learning in a modern education paradigm. The research was conducted by relevant literature review along with reflective analysis on sub-context such as creativity, educational development, pedagogical methods, important factors behind of creativity development and technology-learning systems affects.

Various issues may become a supportive factor or barrier for creativity development in educational processes. Technology in an education field provides many opportunities for creativity enhancement, among which supports to enhance curiosity to develop some skills to improve student's cognitive processes and engagement as well as to increase intrinsic motivation, self-regulation.

Authors attempted to consider all the benefits, challenges and risks related to enhancing creativity with the help of technology in modern educational paradigm. Many studies have been analyzed in order to answer main research question: How technology-pervasive learning environment can enhance stimulation and development of creativity among students.
\end{abstract}

Keywords - Creativity, models of creativity, barriers for creativity, pervasive Learning: e learning, cyber learning, social media, networking technologies, educational paradigm

\section{Introduction}

Although, many studies on creativity have been conducted in different disciplines by various researchers, there still remain gaps and unanswered questions. It is important to analyze the context with proven methodology and explore the potential outcomes, which affects individuals and groups. Contemporary education should equip a student with skills to acquire information, encourage curiosity and enhance critical thinking, which creates circumstances for novel approach in education. Our research has been planned to address the following research questions "How creativity is related to students' academic and career achievements?", "Does external and internal factors enhance or lessen creativity?", and "How technology and pervasive learning environment can enhance stimulation and development of creativity among students?"

A contemporary educational system should not only concentrate on providing the basic knowledge and experience, but also to assist students in discovering their own 
potential and opportunities in further career development and achievements. Skills related to knowledge application, problem-solving, adaptation to social, economic and other changes in their society as well as developing of own autonomy, responsibility and self-regulation seems to be very important nowadays [60].

\section{Literature Review (Background of the Study)}

\subsection{Theories explaining relation between creativity and education}

The relationship between creativity and education is complex and includes many significant elements. Some researchers emphasize the important role of creativity in a learning process; some relate it to children education only, some to a discovery process or result. It is important to apply the complex approach in creativity development, where educational, sociocultural, and individual factors are considered. Those dimensions have strong impact on creating opportunities to enhance learner's creative approach during the educational process. Creativity has to be defined in terms of novelty, flexibility, and divergent thinking, but also productivity and applicability of gained knowledge and experience [55], [59].

The first attempts to analyze creativity can be grouped as process-oriented models, person-oriented models, and product-oriented models. Process-oriented models include "phase model", proposed by Cropley and Cropley [12] consisting of seven basic phases of creative process: preparation, activation, cogitation, illumination, verification, communication, and validation. Those phases were related to four "P's" of creativity, including person (personality, intellect, traits, attitudes, values and behaviour), process (stages of thinking people go through when overcoming an obstacle or achieving a goal), product (characteristics of artefacts or outcomes of new thoughts, inventions, designs, or systems), and press (the relationship between people and the environment, the situation and how it affects creativity).

Product-oriented models are represented by few types of creativity described by different researchers: Simonton [47] investigated so-called "Big-c" creativity related to outstanding contributions to society, while other scholars explored "Little-c" creativity, meaning useful and important creativities. More recently [5], [21] researchers conducted research on "Mini-c" creativity, which occurs at personal level as a unique, novel and meaningful interpretation of experiences, actions, and events by an individual. Therefore, "Mini-c" creativity is the most integrated into everyday creativity [39] or personal creativity [45].

Among models belonging to a person-oriented group, Intelligence models developed by Sternberg [48] seemed to play an influential role. This model considers three processing skills, which have a crucial influence on successful intelligence: analytical, creative, and practical. Students can learn creativity as a part of problem-solving skills, including generating ideas or solutions, analyzing alternatives and opportunities, and making efficient decisions. In this matter, it is extremely important to perceive creativity as a central cognitive process in education, where creativity has to be combined with practical and analytical skills in teaching. 
Another approach explores creative education through a 5C model. Curiosity in educational processes should be considered at both intellectual and scientific levels. Scientific curiosity from students' side triggers more involved and deep thinking, as well as asking many questions and having doubts or delaying the judgments. $5 \mathrm{C}$ models demonstrate the relation between the student's way of thinking and environmental context, as well as accents a great role of curiosity in an educational process. Therefore, can be applied successfully if attitude and effort from both sides (teacher and learner) will be involved accordingly [62].

In conclusion, creativity has to be successfully implemented in educational field with different levels of success excluding type of school, age of students, and personality of people involved in educational process. Creativity at "mini-c" level seems to be a good starting point for implementing creativity in education in many directions. On the other hand, creativity can be combined with students' development and learning process. It seems to be extremely important developing of the following skills; ability to judge the usefulness of new idea or solution, ability to generate new ideas, skill to improve or modify ideas in order to make them more useful. Moreover, creativity has to be an important component of problem-solving skills in combination with critical thinking, communication and negotiation skills as well as evaluation skills and analytical thinking.

\section{$3 \quad$ Methodology}

\subsection{Problem Statement and Purpose of the Study}

This paper is aimed to explore the relationship between creativity and educational technology, specifically pervasive learning in an educational context. As an essential goal of contemporary education which prepares students to their further professional career, equipped with needed professional knowledge (generation, utilization and dissemination), along with experience (practical, being adoptive and productive to content aware situations), and skills (capabilities, critical thinking, problem solving, flexibility, being imaginative, thinking constructively) [60]. Authors attempted to consider and find out that all essential issues related to enhancing the complementary applications of creativity in modern educational paradigm found to be crucial. The available studies in recent literature have been analyzed in order to answer the research questions to address research aims. Besides, the objective of this study is also to provide descriptive insight into the types of issues studied previously and find out the most common understandings with illustrative examples from educational technology domains [67].

\subsection{Research Questions}

To achieve the main goal of this study, the main effort was taken in order to seek the answers for the following research questions:

RQ1: How creativity is related to students' academic and career achievements? 
RQ2: Does external and internal factors enhance or lessen creativity?

RQ3: How technology and pervasive learning environment can enhance stimulation and development of creativity among students?

\subsection{Research Method}

The research conducted by relevant literature review along with concentration of the diversity of terminology which reflects the analysis on sub-categories such as: creative potential and abilities, role of cognition in learning processes and developing creativity skills and capabilities in educational context with technology usage. The body of literature review includes studies that address related research problems. The main objective is going to be exploration of the relationship between creative abilities of young generation in educational domain as well as new knowledge generation by using pervasive learning approach.

The research conducted with scoping searches, associated with the relevant literature of reviews, their analysis and synthesis. Although the various research methods could be used to determine the relations among variables (main variables of this study are creativity, educational context and technology usage namely pervasive learning) authors concentrate to use the form of Scoping Review and Critical Review approaches combined as a main starting point [66]. This research is the first step of understanding the concepts for analyzing and discussing the relevant theories to follow a base for further empirical researches. Scoping review used as preliminary assessment with Critical review, which helps researchers to understand and constitute the concepts around existing literature models, approaches and insights to highlight the important topics and conclude interpretation of existing thoughts. Besides, it also helps to develop the process of evaluation in order to reach conceptual knowledge.

\section{Discussions}

\subsection{Factors enhancing creativity development}

Analyzing factors maintaining or enhancing creativity, the following issues have to be considered: motivation and self-determination, teaching approach and individual differences.

Educational institution can enhance creativity development among students through applying policy, developing assessments, preparing teachers, promoting creativity, etc. It is necessary to promote a non-traditional way of teaching, considering collaborative teaching relationships, creating appropriate psychosocial atmosphere, encouraging students to contribute novel, original and inventive ideas. Additional condition for creativity enhancing is promoting independent thinking, spontaneity and initiative, as well as work on students' potential (intellectual, emotional, motivational), applying such methods as problem-solving, heuristic approach, learning through discovery, learning through research. Developing and using students' imaginative potential may 
increase their cognitive and social capabilities, as well as decrease a fear of being exposed to different new experiences [13].

The next important supporter is intrinsic motivation or self-determination. It is important to analyze the relation between motivational orientation and person's performance. Few studies demonstrated, that intrinsic motivation (e.g. interest, pleasure, satisfaction) can reinforce creativity, while extrinsic motivation may inhibit it. Additionally, individuals who perceive a reward as a "bonus" used to be more intrinsically motivated and more creative. Interesting results demonstrate that, low-skill students demonstrated higher creativity when expecting evaluation in comparison with high-skill students [18]. In a situation when students perceived an academic committee as a possibility for receiving confirmation of their capabilities or recognition from respected experts, creativity was reinforced [2]. In conclusion, rewards or evaluations perceived as informative, constructive or useful may have a positive impact on intrinsic motivation to be creative.

Recent studies analyzed a relation between individual characteristics and creativity. Positive mood, openness to experience, and positive self-image are related to creativity, encouraging person to be more creative, applying different experiences, developing their own potential and avoidance of psychologically uncomfortable feelings. High selfefficacy is related to greater creativity. Although all of the mentioned factors are important for creativity as demonstrated in various studies, the relation between them is not very clear [10].

\subsection{Barriers to develop creativity in the classroom}

Contemporary literature review presents studies on possible barriers that can suppress creativity in an educational field. Those barriers can be divided into three groups: teacher's attitude and practice, types and structure of assessments, and students' beliefs regarding creativity.

The basic barrier can be established by the methodology and philosophy teachers apply in their teaching practice, which could not change a lot since educational system was established. Traditionally, a teacher transmits information, asks questions, while students wait for possibility to share their ideas as well as for teacher's evaluation [31], [56]. This approach gives little opportunity for learners to express their unusual ideas or interpretations as well as to explore their insights. Additionally, the social role of a teacher provides specific experiences and shapes appropriate attitudes, beliefs and assumptions regarding teaching and learning processes, which may suppress creativity development among learners and teachers [40], [57]. Those experiences and beliefs are created by making pressure on teachers to confirm to the external standards and programs, standardized evaluations and teaching approach, what usually do not include creativity as one of the learning standards or outcomes [29].

Even if teachers are supporting the idea of creativity, the educational system and convergent approaches to teaching make challenging the process of implementing of creativity in an educational process as well as creates many misbeliefs and attitudes about creativity among educators and students. The ideal student in contemporary educational system with all the paper work and pressure on teachers, is usually viewed 
as confirming and compliant [42]. In addition, some studies reported that teachers may have not clear understanding of creativity [35] which blocks students' creative potential development, and causes difficulties with integration of creativity into curriculum and establishes of various biases.

The next barrier to develop creativity in the classroom is educators' biases about creativity. The most common misbelief is tendency to use as synonyms creativity and originality, while last one is considered as an attribution of creativity only [44]. Big-C bias is one of the most widespread misinterpretations of creativity, when people think about creativity in relation with the most legendary creators, discoverers and great minds known all over the world. That misbelief among educators influences many issues, such as expectations from student's creative expression, or acceptance of brilliant ideas or solutions. In this case, mini-c creativity should be recognized as an important role in the classroom, which allows to encourage student's creative expressions, being more open for creative suggestions and more efficient in students' knowledge and skills measurements [58]. Additionally, educators will not mistakenly believe that real creativity is strictly related to high level of giftedness and transferring creativity development to some special places for gifted education.

Finally, educators are tended to believe that creativity requires some distinguishing result or product, what makes an evaluation process easier in comparison with Smallerc creativity, when teachers' judgment can be more subjective. That product bias creates a risk of focusing only on the result and overlooking the creative potential of students [43].

The next group of barriers is related to nature and structure of given to student's tasks or assessments. Recent studies show that students in the game-like conditions were significantly more willing to take intellectual risks necessary for creative expressions in comparison with school-like tasks. At the same time, competitions and appropriate rewards can increase individual and group motivation to be creative [2]. Although, there are studies showing a negative influence of rewards to students' motivation [9], some of the researchers delivered evidences of its positive influence [17] Actually, using of rewards may have ambivalent influence on the students' performance and achievements, dividing their attention and demotivating for choosing a challenging task, taking intellectual risks or being involved into creative expressions.

Feedback that students receive from their educators with its motivational aspect considered as an important barrier for enhancing creativity in a classroom. Teachers used to emphasize or display the "best" work of their students as a motivating strategy. However, some of the recent studies shows its negative influence on students' motivation. Creativity can be suppressed if educational conditions are supported by extrinsic motivation such as rewards, social comparison, competitions and social judgments. That is why comparison to achievements of others and based on its evaluation may cause negative feeling (stress or fear), what decreases students desire and capabilities for creative thinking [45], [9]. Additionally, studies conducted by cognitive psychologists proved negative impact of extrinsic motivation (i.e. expected reward or evaluation) on creativity among adults [14]. It was also proved, that environmental factors, such as expected rewards, evaluations or competitions can have a profound influence on motivational orientation. 
Finally, the last group of barriers are related to the students' beliefs, including selfefficacy, self-esteem, which may determine whether creativity will be developed or suppressed in an educational process. Creative self-efficacy is one of important selfbeliefs, defined as a self-evaluation of person's imaginative potential and ability to generate original, novel and adaptive solutions, ideas, or behaviors. Those beliefs are strictly related to students' motivational beliefs and academic ambitions [6] educator's evaluations of creativity expression [21], creativity evaluations from supervisors [63] and students' desire to take a risk for intellectual tasks [6]. It was proved that healthy self-efficacy beliefs can help students to perceive a risk as a challenging opportunity [7]. In this case, students are more willing to raise and discuss unusual questions, share novel and unique ideas, and to experiment new solutions, etc. As a result, not being afraid of making mistakes, feeling less competent, what considered as risky because of being in an uncertain situation. To decrease the mentioned issues impact, teacher's feedback has to be supportive, informative, constructive and positive.

\subsection{Pervasive learning and technology usage for creativity development}

Since the term coined by Pontefract [36] as "pervasive learning" which defined the key elements of the learning enhanced by formal, informal and social experiences. Learning become more in collaborative, inter-connected, continuous, communicative and social community-based. It includes different learning actions such as in-class (physical classroom), out of the class (virtual classroom), game-based, e-learning, conferences, and forums in formal context; similarly mentoring, web conferencing, webinars, workshops, podcasts, case studies in informal context; on the other hand, similarly social web tools such as wikis, blogs, micro blogging, friending, tagging, user generated content, messaging platforms in social context.

Although the pervasive learning model applied and studied in organizational context for employees, but also it is used for e learning through the other learning and educational context to motivate learners. As emerging approaches of new educational paradigm, accelerate the learning activities throughout all channels and platforms to learners in order to structure the content and context. The nature of content availability at any time and from anywhere make changes in e-learning and social learning. Therefore, social learning environments and advancement of technology and its utilization provides and facilitates better content deliveries among user groups and individuals. Example of the mobile phone usage recently has tremendous effects on sharing ideas, discussions and other social knowledge disseminations. The technology (mobile pervasive learning technologies, applications and pervasive computing, etc.) available today could enhance the accessibility and effectivity of utilization to sources and interaction among peers in order to reach innovative applications and programs.

In terms of technology side, pervasive learning supported by computer science and information systems developments in e learning and $\mathrm{m}$ learning. Recent technological developments on user-friendly interfaces, computer or related device-human interactions, cloud computing, learning by interactivity, web platforms, mobile apps, mobile devices (phones, tablets) [51\}, connectivity, seamless technologies, functionality and versatility, asset libraries, artificial intelligence, augmented reality, 
RFID, client-server architecture, multiple simultaneous user platforms, IoT (Internet of Things such as environmental sensors, barcodes, pressure sensors, positioning-GPS, navigations, holographic displays, 3D image processing and printing, fog screen, etc), speech-voice recognition, eye tracking, biometrics (fingerprints, iris scanner, voice, face recognition), etc. have various affects and results for new educational paradigm.

Those mobile devices which support educational platforms by having such roles as data collection (big data and analysis) [24] content representation tool (text, image, audio and video), communication with peers, location based like navigation (GPS, RFID), notification tools (messages received by sender/instructor). Those technologies also refer and defined as on-demand learning, learning by playing apps and tools, group and individual learning models.

\subsection{Studies on the relationship between pervasive learning, technology usage and creativity}

Technology role and impact in learning environment is under exploration by scientists and practitioners. It is necessary to consider all the benefits, challenges and risks related to this matter.

The strong side of technology use in educational process is integration of wide range of graphics, animation, sound, text in a way adjusted to the specific learning objectives and leaner needs. The distinguishing role of technology justifies in some cognitive approaches [28]. Other researchers suggest providing various features of technology may keep learners engaged in learning process through keeping attention and interest to the studied material [32].

It is very important to create a pervasive environment, which may be adaptable to students' interests, beliefs, attitudes, preferences, goals, knowledge and experience. That is why, technology use may help to develop creative and critical thinking skills, problem-solving skills, and study skills as additional benefit of its usage. The most important benefits of pervasive environment could be said as monitoring and storing detailed information, commenting learners' progress and achievements, checking learning outcomes, accumulation of learning experience and creating individual portfolio, providing individual feedback regarding student's learning outcomes [1].

The most significant feature of pervasive environment is providing plenty of various digital sources to each specific course, what in combination with non-digital sources may enhance the learning process [49] which students have to search, select, retrieve and share opinions or discoveries based on analysis of information from multiple sources [1].

Literature on e learning demonstrates the importance of interaction between individual and group knowledge construction, considering processes of discussion, internalization and externalization of the knowledge as very important approaches [11]. According to Du Plessis' [16] study, knowledge management impact on creativity development is significant and is possible due to collaboration [23] continual learning, and knowledge sharing [25]. As a result, students may apply knowledge for producing creative ideas or solutions, strategies or mechanisms [24]. 
Other important relation is between creativity and self-regulation. Learners with a high level of self-regulation tended to be more active during education process in terms of motivation, cognition and behavior [26]. Those learners are more successful in independent improving their study skills, in creating beneficial for them learning environment, in choosing the form and content of necessary instructions, in assessing own success and progress [50]. In addition, important role in relationship between selfregulation and creativity have self-perceived creativity, time management skills [65] self-concordance [19] and autonomous orientation [22].

Interesting and significant studies were conducted on relation between student's acceptance of technology and creativity development. Lee and Ryu [26] studied the discovery of the relation between technology acceptance and learner success, as a result of findings it should be noted that cognitive engagement is a key variable in relation between technology self-efficacy, perceived richness of technology, perceived learner control and perceived usefulness [30]. It seems to be significant role of prior knowledge and experience [37] as well as confidence in student's knowledge and skills or selfefficacy [34], what may develop expectations regarding learning outcomes and role of technology use in academic success. Perceived richness of pervasive learning influences the cognitive engagement, being attractive for learner and being able to increase their intrinsic motivation [4]. It was discovered that technology self-efficacy has a significant influence on learner acceptance of this technology use in educational process [41] and is predictive of perceived usefulness of technology [20].

It has been proved that intrinsic motivation is a significant and necessary condition to academic achievements and learning success [33], [60]. Other studies stated, that cognitive engagement is one of the most important outcomes of intrinsic motivation, which can be measured based on such constructs as interest, curiosity, attention, and creativity [64]. Triggered curiosity is supposed to enhance creativity development as well as to maintain interest and cognitive engagement [3]. Technology offers a wide range of possible activities, which may help to reinforce intrinsic motivation of learner through increasing student's interest, attention and cognitive engagement.

Research conducted by Selim [52] offered a classification of e-learning success factors, among which was a learner's perception of interactivity. Additionally, it was stated, that interactivity is highly valued by learners [54] what can influence perceived usefulness of technology in educational process. Continuously, a high level of interactivity is considered as a key point for effectiveness of technology-mediated learning [38], as well as for reinforcement of intrinsic motivation in learning [27]. Interactivity has to become an important feature of modern technology used in educational process [46]. However, high interactivity does not influence understanding [15] or prediction of achieving learning outcomes [53].

In conclusion, technology role in contemporary world and education is extremely significant, but use of it needs to be adjusted to the learning objectives and student's abilities. Technology in education process provides many advantages related to academic achievements as well as some disadvantages. Technology may support to enhance curiosity, creativity or other attitudes and skills development, as well as can improve student's attention, memory and imagination, but also may become a distractor in learning process [8], [67]. 


\section{Conclusion}

The main purpose of this paper was to investigate the role of creativity in a contemporary education paradigm, and to analyze the potential mechanisms of creativity development. A significant part of this research is to explore the potential and possibilities of the application of modern technology in a learning environment in terms of stimulation and development of the creativity among young generation.

Presented above discussions demonstrate a number of factors influencing the creativity development from personal, situational, and normative perspectives [67]. Various issues may become a supportive factor or barrier for creativity development in educational paradigm. Additionally, there are many misinterpretations and misunderstandings related to the core meaning of creativity, what supports wrong belief regarding creativity, develops faulty expectations, decreases student's motivation, and makes more challenging implementation of any related to creativity content into educational process.

Technology in an educational process offers many advantages as well as some obstacles. There are different learning modalities, which may combine digital with nondigital sources in order to improve learning process and develop creativity of the students. It is important to remember that some skills which learners need to develop to increase benefits from pervasive-learning environment during learning process. For instance, technical, meaning-making, self-regulation ability, knowledge management ability, decision making skills etc.

Various studies proved that strong relationship between technology use and creativity enhancement through reinforcing students' intrinsic motivation, selfregulation, curiosity, self-efficacy and knowledge exchange. It has been discussed that intrinsic motivation is a necessary and significant presuming condition to learning success and academic achievements. Cognitive engagement was explored as a key variable in relation between technology self-efficacy, perceived richness of technology, perceived learner control and perceived usefulness of technology. Pervasive-learning environment provides many opportunities, among which may be mentioned support to enhance curiosity and creativity, to develop some skills, to improve student's cognitive processes and cognitive engagement, as well as to increase intrinsic motivation.

Besides that, use of various forms of technology may assist in increasing the role of pervasive learning as well as reinforce factors enhancing creativity development and lessen some of the barriers discussed above for creativity development through creating variety in types of assessments, enhancing imagination, minimizing teacher's subjectivity in teaching and grading, reinforcing students' self-belief in their own imagination and potential to create novel and unusual solutions without fear of being not accepted or criticized in front of others [58]. As a result of that, teachers may expect an increase of academic ambitions among learners, cognitive involvement and intrinsic motivation, as well as decreasing of conformity and the risk of taking high intellectual assignments.

Creativity in education became a vital point in order to be successful in a contemporary world. Numerous explorers applied various research methods such as case studies, experiments, tests and simulation games to gather data demonstrating the 
role of creativity and possibilities of its development in both educational and professional spheres. Despite of great contribution in comprehension of the subject, there is significant disagreement between theorists in terms of creating informational background as well as between researchers in terms of empirical investigating the subject and providing a non-questionable interpretation of received data.

Overall, it is necessary to remember that creativity is a complex phenomenon that developed from a combination of different variables and perspectives. Therefore, it is necessary to conduct more research on possibilities of psychological and technological tools involved into developing of pervasive learning, whereas results in creativity reinforcement.

\subsection{Future research directions}

Although there are various studies exploring creativity by itself and its relation with educational sphere, some of important directions need to be examined. It seems to be extremely significant to move creativity to one of the center points in educational programs. This requires additional exploration and clarifying the relationships between creativity and learning. The other issue needs to be examine is the connection between current research on creativity and educator's preparation and development in terms of equipping teachers with tools for supporting and enhancing creativity in their classrooms.

The next possible research direction is related to establishing the cooperation between creativity researchers and educators in terms of sharing findings as well as making them being applied in educational process [61]. Another direction for further study is the technology impact on learning environment, students' achievements and opportunities for teachers and students as well.

Some potential research questions exploring the impact of pervasive environment and technology use on educational achievements are; What types of tools and strategies can support the most effectively students and teachers? How can we decrease any risk of technology which might have negative influence at learning process? What are the possibilities of modern technology in terms of increasing creativity and curiosity as well as sustaining student's engagement and interest? Is it possible to range the factors of learner's creativity reinforcement according to type of course or personality and age of students?

\section{References}

[1] Alvarez, C., Salavati, S., Nussbaum, M., \& Milrad, M. (2013). Collboard: Fostering new media literacies in the classroom through collaborative problem solving supported by digital pens and interactive whiteboards. Computers and Education, 63, 368-379. https://doi.org/10.1016/j.compedu.2012.12.019

[2] Amabile, T. (2013). Componential theory of creativity. In E. Kessler (Ed.), Encyclopedia of management theory (pp. 135-140). Thousand Oaks, CA: SAGE Publications, Inc.

[3] Arnone, H. P., Small, R. V., Chauncey, S. A., \& McKenna, H. P. (2011). Curiosity, interest and engagement in technology-pervasive learning environments: A new research agenda. 
Paper-Pervasive Learning and Technology Usage for Creativity Development in Education

Educational Technology Research and Development, 59, 181-198. https://doi.org/10.1007/s11423-011-9190-9

[4] Baggio, B. G. (2010). Creating supportive multimedia learning environments. In H. Song \& T. Kidd (Eds.), Handbook of research on human performance and instructional technology (pp. 88-103). Hershey, PA: IGI Global. https://doi.org/10.4018/978-1-60566-782-9.ch005

[5] Beghetto, R.A. (2009). In search of the unexpected: Finding creativity in the micromoments of the classroom. Psychology of Aesthetics, Creativity, \& the Arts, 3, 2-5

[6] Beghetto, R.A. (2006). Creative self-efficacy: Correlates in middle and secondary students. Creativity Research Journal, 18, 447-457. https://doi.org/10.1207/s15326934crj1804 4

[7] Byrnes, I. P. (1998). The nature and development of decision-making: A self-regulation model. Hillsdale, NJ: Erlbaum.

[8] Carr, N. (2010). The shallows: What the Internet is doing to our brains. New York, USA: W.W. Norton \& Company.

[9] Collins, M.A., \& Amabile, T.M. (1999). Motivation and creativity. In R.J. Sternberg (Ed.), Handbook of creativity (pp.297-312). Cambridge: Cambridge University Press.

[10] Costa, S., Paez, D., Sanchez, F., Garaigordobi, M., Gondim, S. (2015). Personal factors of creativity: A second order meta-analysis. Journal of Worl and Organizational Psychology. 31, 165-173. https://doi.org/10.1016/j.rpto.2015.06.002

[11] Cress, U., Held, C., \& Kimmerle, J. (2013). The collective knowledge of social tags: Direct and indirect influences on navigation, learning, and information processing. Computers \& Education, 60(1), 59-73. https://doi.org/10.1016/j.compedu.2012.06.015

[12] Cropley, A., \& Cropley, D. (2008). Resolving the paradoxes of creativity: An extended phase model. Cambridge Journal of Education, 38, 355-373. https://doi.org/10.1080/03057640802286871

[13] Cujbă, T.O. (2010). Considerations on Creativity Motivation. Buletinul Universitanii Petrol - Gaze din Ploiesti. Ştiinele Educaniei. Vol. LXII (2), 154 - 159

[14] Deci, E., \& Ryan, R. M. (1980). The empirical exploration of intrinsic motivational processes. In L. Berkowitz (Ed.), Advances in Experimental Social Psychology (pp. 39-80). New York: Academic. https://doi.org/10.1016/S0065-2601(08)60130-6

[15] Domagk, S., Schwartz, R. N., \& Plass, J. L. (2010). Interactivity in multimedia learning: An integrated model. Computers in Human Behavior, 26, 1024-1033. https://doi.org/10.1016/j.chb.2010.03.003

[16] Du Plessis, T. (2007). Permanent linking: A virtual learning environment content integration strategy. In I. Morley (Ed.), The value of knowledge (pp.85-97). Oxford, London: Interdisciplinary Press.

[17] Eisenberger, R., \& Shanock, L. (2003). Rewards, intrinsic motivation, and creativity: A case study of conceptual and methodological isolation. Creativity Research Journal, 15, 121-130.

[18] Hennesey, B., \& Amabile, T. (2010). Creativity. Annual Review of Psychology, 61, 569598. https://doi.org/10.1146/annurev.psych.093008.100416

[19] Hon, A. H. Y. (2011). Enhancing employee creativity in the Chinese context: The mediating role of employee self-concordance. International Journal of Hospitality Management, 30, 375-384. https://doi.org/10.1016/j.ijhm.2010.06.002

[20] Hsu, M. K., Wang, S. W., \& Chiu, K. K. (2009). Computer attitude, statistics anxiety and self-efficacy on statistical software adoption behavior: An empirical study of online MBA learners. Computers in Human Behavior, 25, 412-420. https://doi.org/10.1016/i.chb.2008.10.003

[21] Kaufaman, J.C. \& Beghetto, R.A. (2009). Beyond big and little: the four C model of creativity. Review of General Psychology, 13, 1-12. https://doi.org/10.1037/a0013688 
[22] King, L., \& Gurland, S.T. (2007). Creativity and experience of creative task: Person and environment effects. Journal of Research in Personality, 41, 1252-1259. https://doi.org/10.1016/j.jp. 2007.01.005

[23] Kulakli, A. (2005). Yeni ürün geliştirme sürecinde bilgi paylaşımının önemi ve bir uygulama. İstanbul Ticaret Üniversitesi Fen Bilimleri Dergisi, 4(8), 99-114.

[24] Kulakli, A., and Birgün, S. (2011). Müşteri merkezli operasyonel bilgi yönetimi için veri yönetiminin ölçülmesi. İTÜDERGİSİ/b, 2(1), 37-48 (Published paper form in 2005)

[25] Kulakli, A. \& Mahony, S. (2014). Knowledge creation and sharing with Web 2.0 tools for teaching and learning roles in so-called University 2.0. Procedia-Social and Behavioral Sciences, 150, 648-657. https://doi.org/10.1016/j.sbspro.2014.09.084

[26] Lee D. Y. \& Ryu H., (2013). Learner Acceptance of a Multimedia-Based Learning System Intl. Journal of Human-Computer Interaction, 29: 419-437 https://doi.org/10.1080/104 $\underline{47318.2012 .715278}$

[27] Liaw, S.-S. (2008). Investigating students' perceived satisfaction, behavioral intention, and effectiveness of e learning: A case study of the blackboard system. Computers \& Education, 51, 864-873. https://doi.org/10.1016/i.compedu.2007.09.005

[28] Mayer, R. E. (2005). Cognitive theory of multimedia learning. In R. E. Mayer (Ed.), The Cambridge handbook of multimedia learning (pp. 31-48). New York, NY: Cambridge University Press. https://doi.org/10.1017/CBO9780511816819.004

[29] McNeil, L.M. (2000). Contradictions of school reform: Educational costs of standardized testing. New York: Routledge.

[30] Ngai, E., Poon, J., \& Chan, Y. (2007). Empirical examination of the adoption of WebCT using TAM. Computers \& Education, 48, 250-267.

[31] Oakes, J. \& Lipton, M. (2007). Teaching to change the world (3 $3^{\text {rd }}$ Ed.) Boston: McGraw

[32] Park, S., \& Lim, J. (2007). Promoting positive emotion in multimedia learning using visual illustrations. Journal of Educational Multimedia and Hypermedia, 16, 141-162.

[33] Patrick, H., Ryan, A., \& Kaplan, A. (2007). Early adolescents' perceptions of the classroom social environments, motivational beliefs, and engagement. Journal of Educational Psychology, 99, 83-98. https://doi.org/10.1037/0022-0663.99.1.83

[34] Pintrich, P. R., Schunk, D. H., \& Meece, J. L. (2008). Motivation in education: Theory, research, and applications (3rd ed.). Upper Saddle River, NJ: Merrill.

[35] Plucker, J.A., Beghetto, R.A., Dow, G.T. (2004). Why isn't creativity more important to educational psychologists? Potentials, pitfalls, and future directions in creativity research. Educational Psychologist, 39, 83-96. https://doi.org/10.1207/s15326985ep3902_1

[36] Pontefract, D. (2013). Flat Army - Creating a Connected and Engaged Organization, JosseyBass, Wiley. USA

[37] Potosky, D. (2002). A field study of computer efficacy beliefs as an outcome of training: The role of computer playfulness, computer knowledge, and performance during training. Computers in Human Behavior, 18, 241-255. https://doi.org/10.1016/S07475632(01)00050-4

[38] Proske, A., Narciss, S., \& Körndle, H. (2007). Interactivity and learners' achievement in web-based learning. Journal of Interactive Learning Research, 18, 511-531.

[39] Richards, R. (2007). Everyday creativity: our hidden potential. In R. Richards (Ed.), Everyday creativity and new views of human nature: Psychological, social and spiritual perspectives. Washington DC: American Psychological Association https://doi.org/10.10 37/11595-001

[40] Richardson, V. (2003). Preservice teachers' beliefs. In J. Raths and A.C. McAninch (Eds.), teacher beliefs and classroom performance: The impact of teacher education. Greenwich, CT: Information Age Publishing. 
[41] Roca, J.C., \& Gagne, M. (2008). Understanding e-learning continuance intention in the workplace: A Self-determination theory perspective. Computers in Human Behavior, 24, 1585-1604. https://doi.org/10.1016/j.chb.2007.06.001

[42] Runco, M.A. (2007). Creativity. Theories and themes: Research, development, and practice. Burlington, MA: Elsevier Academic Press.

[43] Runco, M.A. (2005). Motivation, competence, and creativity. In A.Elliott and C.Dweck (Eds.) Handbook of achievement motivation and competence. New York: Guilford.

[44] Runco, M.A. (2004). Creativity. Annual Review of Psychology, 55, 657-687.

[45] Runco, M.A. (2003). Education for creative potential. Scandinavian Journal of Educational Research, 47, 317-324.

[46] Safieddine F., Ismail R. \& Kulakli, A. (2017). E-Universities: Reflective Analysis into Technological Trends. Procedia-15th International Conference e-Society 2017, ISBN: 978989-8533-60-9, 179-186.

[47] Simonton, D.K. (1994). Greatness. New York: Guilford

[48] Sternberg, R.J. (2002). Raising the achievement of all students: teaching for successful intelligence. Educational Psychology Review, 14, 383-393. https://doi.org/10.1023/A $: 1020601027773$

[49] So, W. W. M. (2012). Creating a framework of a resource-based e-learning environment for science learning in primary classrooms. Technology, Pedagogy and Education, 21(3), $317-$ 335.https://doi.org/10.1080/1475939X.2012.719399

[50] Sha, L., Looi, C., Chen, W., Seow, P., \& Wong, L. (2012). Recognizing and measuring selfregulated learning in a mobile learning environment. Computers in Human Behavior, 28, 718-728. https://doi.org/10.1016/j.chb.2011.11.019

[51] Seker, S. E., \& Kulakli, A. (2016). Macroeconomic ICT Facts and Mobile Telecom Operators via Social Networks and Web Pages. Journal of Economics Business and Management, 4(2), 99-103. https://doi.org/10.7763/JOEBM.2016.V4.374

[52] Selim, H. M. (2007). Critical success factors for e-learning acceptance: Confirmatory factor models. Computers \& Education, 49, 396-413. https://doi.org/10.1016/j.compedu. 2005.09.004

[53] Sims, R. (2003). Promises of interactivity: Aligning learner perceptions and expectations with strategies for flexible and online learning. Distance Education, 24, 87-103. https://doi.org/10.1080/01587910303050

[54] Shen, C.C., \& Chuang, H.M. (2009). Exploring User's Attitudes and intentions toward the Interactive Whiteboard Technology Environment. International Review on Computers and Software, 5 (2), 200-208.

[55] Shubina I., (2017). Creativity in psychotherapy: the possibilities of its utilization. The European Proceeding of Social \& Behavioural Sciences. XXII, 99-111. eISSN: 2357-1330. https://doi.org/10.15405/epsbs.2017.05.12

[56] Shubina, I. (2014). Development of education system in Kuwait. Scientific papers collection of Military Institute of Kyiv National Shevchenko University. Kiev, 45, 266-274

[57] Shubina I., (2013). The project method and students' competences during learning process in Polish universities. Problems in modern pedagogical education. Seria: Pedagogic and Psychology. 41 (3), 591-596

[58] Shubina I., (2012). The learning outcomes and ways of its measurement in higher education. Scientific papers collection of Military Institute of Kyiv National Shevchenko University. Kiev, VIKNU, 35, 243-250

[59] Shubina, I., (2011a). Life Long Learning - possibility or necessity? Announcements of Union of Scientists. Bułgaria, Sliven, 19, 190-194 
[60] Shubina I., (2011b). Learning with a project method at Polish universities and students competences. Humanization of the educational process: collective work of scientific papers, red. W.I. Szoczenko. - Special edition 7, part II - Slowiansk: SDPU, 190-198.

[61] Shubina I., (2009). The project method using in higher schools. Scientific papers of Military Institute of Kyiv National Shevchenko University. Kiev, 22, 291-298

[62] Tamdogan, O. G., (2006). Creativity in education: Clearness in perception, vigorousness in curiosity. Education for Information, 24, 139-151.https://doi.org/10.3233/EFI-2006-242$\underline{303}$

[63] Tierney, P., \& Farmer, S.M. (2002). Creative self-efficacy: its potential antecedents and relationship to creative performance. Academy of Management Journal, 45, 1137-1148.

[64] Walker, C.O., Greene, B. A., \& Mansell, R.A. (2006). Identification with academics, intrinsic/ extrinsic motivation, and self-efficacy as predictors of cognitive engagement. Learning and Individual Differences, 16 (1), 1-12 https://doi.org/10.1016/j.lindif. $\underline{2005.06 .004}$

[65] Zampetakisa, L. A., Bourantab, N., \& Moustakis, V. S. (2010). On the relationship between individual creativity and time management. Thinking Skills and Creativity, 5(1), 23-32. https://doi.org/10.1016/j.tsc.2009.12.001

[66] Grant, M. J., \& Booth, A. (2009). A typology of reviews: an analysis of 14 review types and associated methodologies. Health Information \& Libraries Journal, 26(2), 91-108. https://doi.org/10.1111/j.1471-1842.2009.00848.x

[67] Shubina, I.and Kulkli, A. (2018). Creativity and pervasive learning in contemporary educational paradigm. 29th International Congress of Applied Psychology, Montreal, Quebec, Canada, June 26-30, 2018.

\section{$7 \quad$ Authors}

Ivanna Shubina is Assistant Professor at American University of the Middle East, Liberal Arts Department, Psychology, Block 3, Building 1, Egaila, Kuwait. She is also a member of International Association of Applied Psychology and Ukrainian Association of Psychologists.

Atik Kulakli is Associate Professor at American University of the Middle East, College of Business Administration, MIS Department, Block 3, Building 1, Egaila, Kuwait.

Article submitted 18 June 2018. Resubmitted 20 July 2018. Final acceptance03 August 2018. Final version published as submitted by the authors. 